\title{
Transvenous Onyx embolization of cavernous sinus dural arteriovenous fistula using a balloon catheter in the arterial side for flow control
}

\author{
Journal of \\ Neurocritical \\ Care

\section{CASE REPORT} \\ Received: July 4, 2019 \\ Revised: August 21, 2019 \\ Accepted: August 22, 2019 \\ Corresponding Author: \\ Seung Kug Baik, MD, PhD \\ Department of Radiology, Pusan \\ National University Yangsan Hospital, \\ Pusan National University School of \\ Medicine, 20 Geumo-ro, Mulgeum- \\ eup, Yangsan 50612, Republic of Korea \\ Tel: +82-55-360-1834 \\ Fax: +82-55-360-1848 \\ E-mail: skbaik9@gmail.com
}

Chul-Hoo Kang, MD'; Jieun Roh, MD'; Jeong A Yeom, MD'; Sang Won Lee, MD, $\mathrm{PhD}^{2}$; Seung Kug Baik, MD, $\mathrm{PhD}^{1}$

'Department of Radiology, Pusan National University Yangsan Hospital, Pusan National University School of Medicine, Yangsan, Republic of Korea

${ }^{2}$ Department of Neurosurgery, Pusan National University Yangsan Hospital, Pusan National University School of Medicine, Yangsan, Republic of Korea

Background: Cavernous sinus (CS) dural arteriovenous fistulas (DAVFs) are abnormal arteriovenous shunts involving the dura mater, located within or near the walls of the CS. Transvenous embolization is considered to be an effective treatment for CS DAVF. We describe a novel technique for the use of transvenous Onyx embolization in the treatment of CS DAVF, which uses a temporary balloon to occlude the arterial side for flow control.

Case Report: A 63-year-old woman presented with ocular pain and ptosis of the left eye. Cerebral angiography showed a left CS DAVF fed by multiple branches of the left external carotid artery. We successfully treated the CS DAVF using transvenous Onyx embolization with temporary balloon occlusion of the proximal feeding artery to decrease the shunted flow.

Conclusion: Transvenous Onyx embolization with flow control via temporary balloon occlusion may be a useful technique for the embolization of CS DAVFs with multiple arterial feeders.

Keywords: Cavernous sinus; Arteriovenous fistula; Endovascular technique; Balloon occlusion

\section{INTRODUCTION}

Cavernous sinus (CS) dural arteriovenous fistulas (DAVFs) are abnormal arteriovenous shunts involving the dura mater, located within or near the walls of the CS [1]. Although the natural course of CS DAVFs is relatively benign, high-risk lesions with venous reflux require treatment due to ocular symptoms, cranial nerve palsy, and venous hypertension.

Currently, endovascular management is the primary treatment for DAVFs. Various methods have been described for the treat- ment of CS DAVFs, including transarterial and transvenous embolization. Transarterial feeder vessel embolization may be performed, but is frequently inadequate for curative treatment. Some lesions derive their meningeal supply from branches of the intracranial circulation which cannot be accessed or embolized safely [2]. Thus, transvenous embolization is generally considered to be a more effective treatment for CS DAVF [1,2]. Onyx (eV3, Irvine, CA, USA) is a new liquid embolic agent that has been found to be useful in treating DAVF $[3,4]$, and transvenous Onyx embolization has been found to be safe and effective as a

(C) 2019 The Korean Neurocritical Care Society

This is an Open Access article distributed under the terms of the Creative Commons Attribution Non-Commercial License (http://creativecommons.org/licenses/by-nc/4.0/) which permits unrestricted noncommercial use, distribution, and reproduction in any medium, provided the original work is properly cited. 
treatment for CS DAVFs $[3,4]$. However, the use of Onyx in a transvenous approach has limitations. Injecting Onyx against the flow of the fistula is technically challenging; the tendency for the compound to follow the direction of flow increases the risk of embolization of a normal draining vein and migration to an unwanted site.

Here, we report the case of a 63-year-old woman with a CS DAVF fed by multiple head and neck arteries, who was successfully treated using transvenous Onyx embolization with temporary balloon occlusion of the proximal feeding artery to decrease the shunted flow.

\section{CASE REPORT}

A 63-year-old woman presented with a 2-month history of ocular pain, incomplete ptosis, and decreased visual acuity of the left eye. Clinically, ocular movement abnormalities suggestive of cranial neuropathy was not observed. Cerebral angiography showed a left-side dominant CS DAVF fed by the bilateral meningohypophyseal trunks of the internal carotid artery, the left distal internal maxillary artery, the left middle meningeal artery, and the left ascending pharyngeal artery. The venous outflow drained into both superior ophthalmic veins (SOVs, left-side dominant) and both inferior petrosal sinuses (IPSs, right-side dominant) (Fig. 1).

The CS DAVF was treated immediately because the patient's symptoms were severe, and we chose the transvenous approach because the lesion involved multiple fine feeding arteries. The procedure was performed using a biplane angiography unit (Axiom Artis zee biplane, Siemens, Forchheim, Germany). After placement of the guiding catheter, heparin was administered as an intravenous bolus (50 IU/ $\mathrm{kg}$ of body weight, 3,000 to 5,000 IU) followed by an infusion of 1,000 IU per hour.

A 6F Envoy guiding catheter (Cordis Corporation, Hialeah, FL, USA) was placed into the proximal left external carotid artery (ECA) for selective angiography. The late venous phase of the left external carotid angiogram revealed the right IPS and internal jugular vein (IJV). Therefore, the right IPS was chosen for the endovascular approach. Another 6F Envoy guiding catheter was placed into the right IJV, and two microcatheters (Excelsior 1018, Stryker, Kalamazoo, MI, USA) were advanced over the guidewire (Synchro 010, Stryker) into the left CS via the right IPS and the intercavernous sinus. One microcatheter was placed at the orifice of the left SOV, and the other on the venous side of the main fistula.

First, a coil was packed through one microcatheter to prevent migration of the Onyx into the SOV. The coil was retrieved after the Onyx embolization. Next, $0.25 \mathrm{~mL}$ of dimethyl sulfoxide (DMSO) was slowly infused through the other microcatheter over a 90-second period. To control the shunted blood flow at the left ECA, a balloon catheter (Scepter C, $4 \times 10 \mathrm{~mm}$, MicroVention Inc., Tustin, CA, USA) was placed into the proximal left ECA. The balloon was inflated, and then the Onyx-18 injection was started. The left ECA angiogram was monitored during the intermittent Onyx-18 injection using a 6F Envoy catheter placed in the left proximal ECA. The procedure was completed as soon as the left ECA angiogram revealed complete obliteration of the DAVF (Fig. 2). In total, $4.4 \mathrm{~mL}$ of Onyx-18 was injected over 66 minutes. The microcatheter used for the Onyx injection was readily retrieved.

No postprocedural complications or additional cranial nerve palsies were observed. The patient was discharged on postprocedure day 10. Her symptoms improved within several weeks, and a transfemoral cerebral angiography at the 6-month post-embolization showed complete obliteration of the CS DAVF (Fig. 3).

\section{DISCUSSION}

CS DAVFs account for $20 \%$ to $40 \%$ of all intracranial DAVFs [5]. Ocular symptoms caused by anterior venous drainage are the most common symptoms of CS DAVF. Aggressive neurological symptoms are rare due to the benign venous drainage pattern, but can occur in association with dangerous venous drainage patterns, including cortical venous reflux (hemorrhagic infarction), deep venous drainage (hemorrhage, edema), and thrombosis of the central retinal vein (blindness) [6]. The spontaneous regression rate of CS DAVFs is high, occurring in $10 \%$ to $50 \%$ of cases [5]. Given the low prevalence of aggressive symptoms and relatively high spontaneous regression rates, most cases can be treated conservatively. However, patients with progressive and intolerable symptoms require more active treatment. CS DAVFs can be treated using a transarterial or a transvenous approach. The transvenous approach is most commonly used for CS DAVFs because the transarterial approach is a more complex and less effective technique.

A wide variety of embolic agents are available for DAVF embolization, including polyvinyl alcohol particles, coils, N-butyl cyanoacrylate (NBCA), and DMSO solvent materials such as Onyx, Squid, and precipitating hydrophobic injectable liquid. Of those, coils and DMSO solvent materials such as Onyx are the most commonly used agents, with each having advantages and disadvantages.

Coils are placed in a controlled manner and are more easily deployed in the desired position than is Onyx. However, coils are 

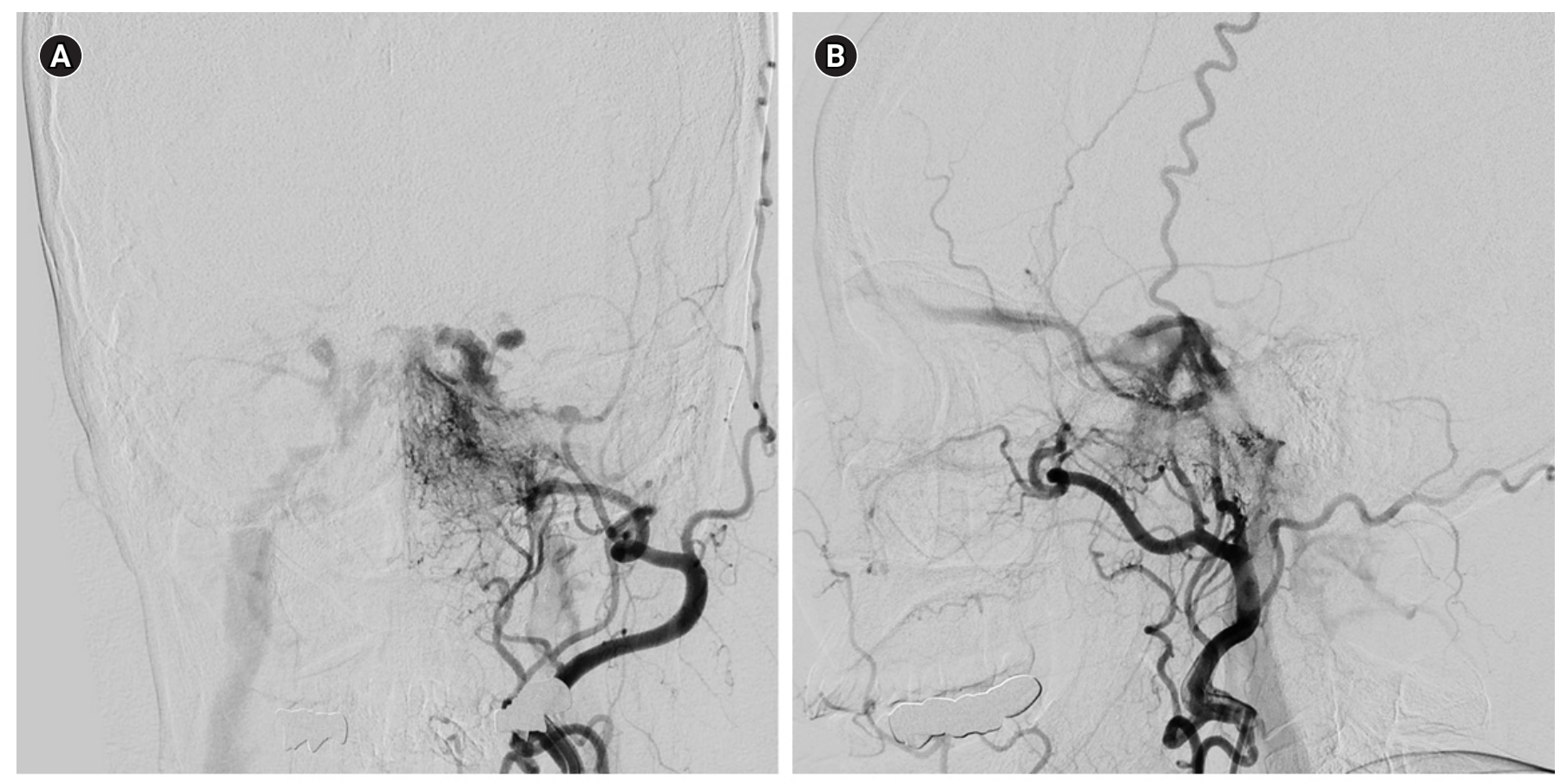

C

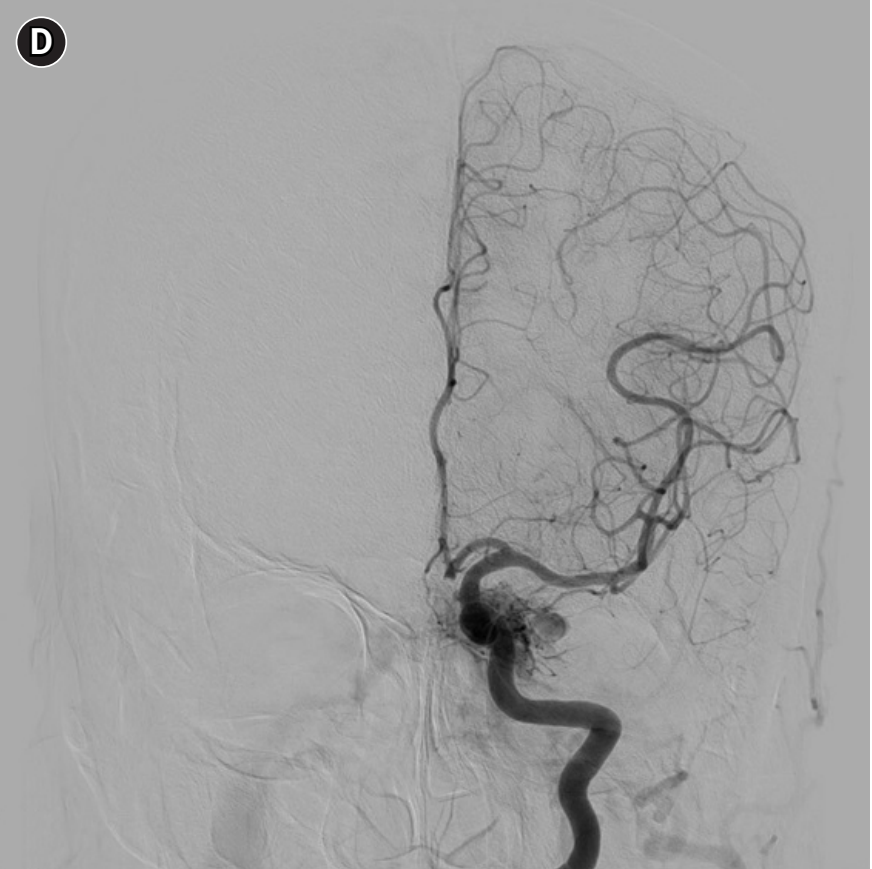

Fig. 1. Left external carotid artery (ECA) angiography, (A) frontal projection and (B) lateral projection, showing a left cavernous sinus (CS) dural arteriovenous fistula fed by the left distal internal maxillary artery, the left middle meningeal artery, and the left ascending pharyngeal artery, drained to the both superior ophthalmic vein (left side dominant) and the both inferior petrosal sinus (right side dominant). (C) Right internal carotid artery (ICA) angiography and (D) left ICA angiography, showing shunted flow from the bilateral meningohypophyseal trunk to the CS.

associated with a lower rate of complete obliteration. Moreover, coils are more thrombogenic than Onyx and can lead to progressive thrombosis causing mass effects. To achieve complete occlusion of CS DAVFs, the CS needs to be densely packed with coils. Nishino et al. [7] found that paradoxical worsening (the devel- opment of new or worsening symptoms or signs after embolization) occurred in $39.4 \%$ of patients after transvenous coil embolization, which was correlated with the volume of coils in the CS [8]. Paradoxical worsening may be attributed to progressive thrombosis of the CS, mass effects from the embolic materials, or 

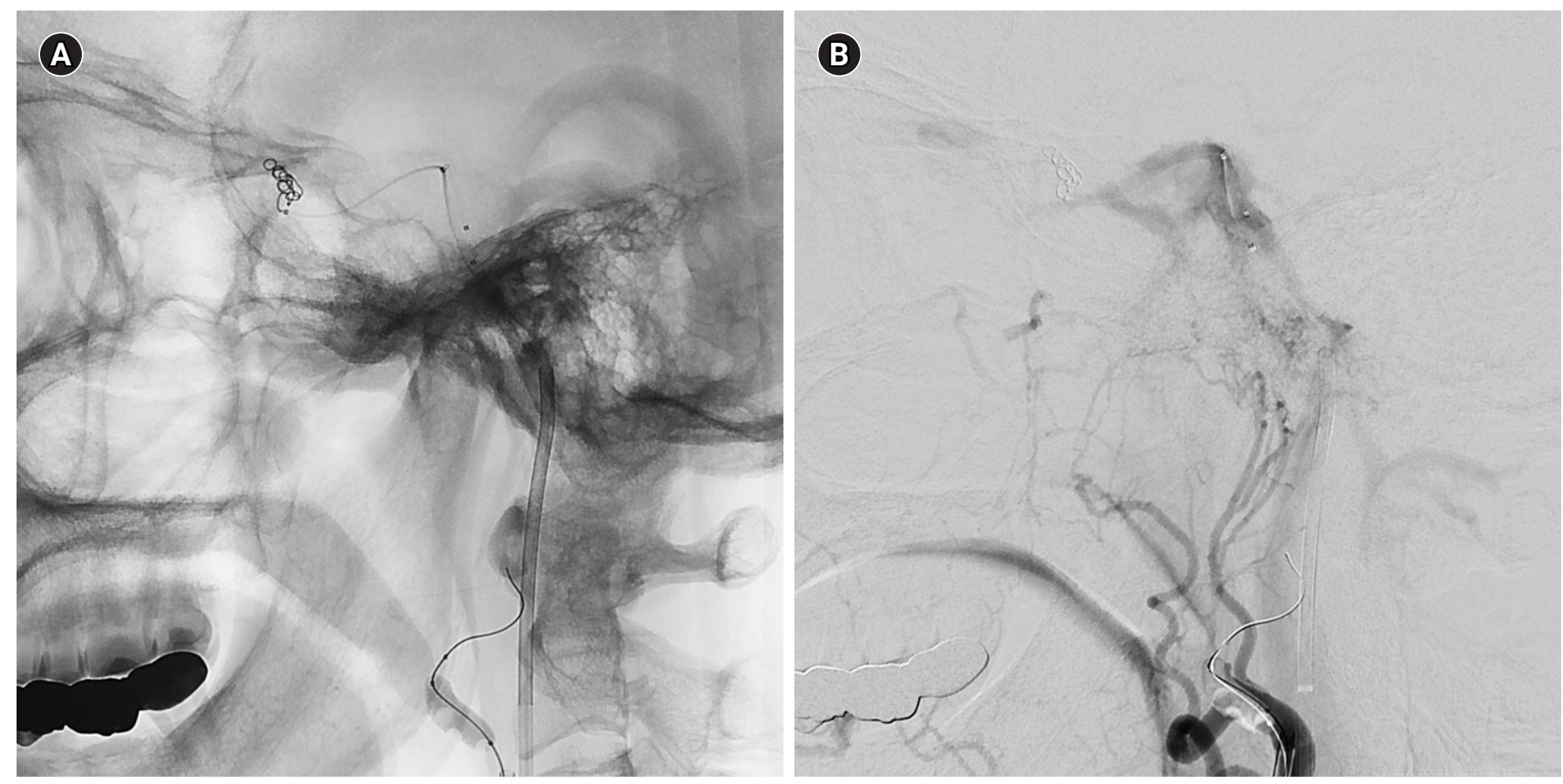

C
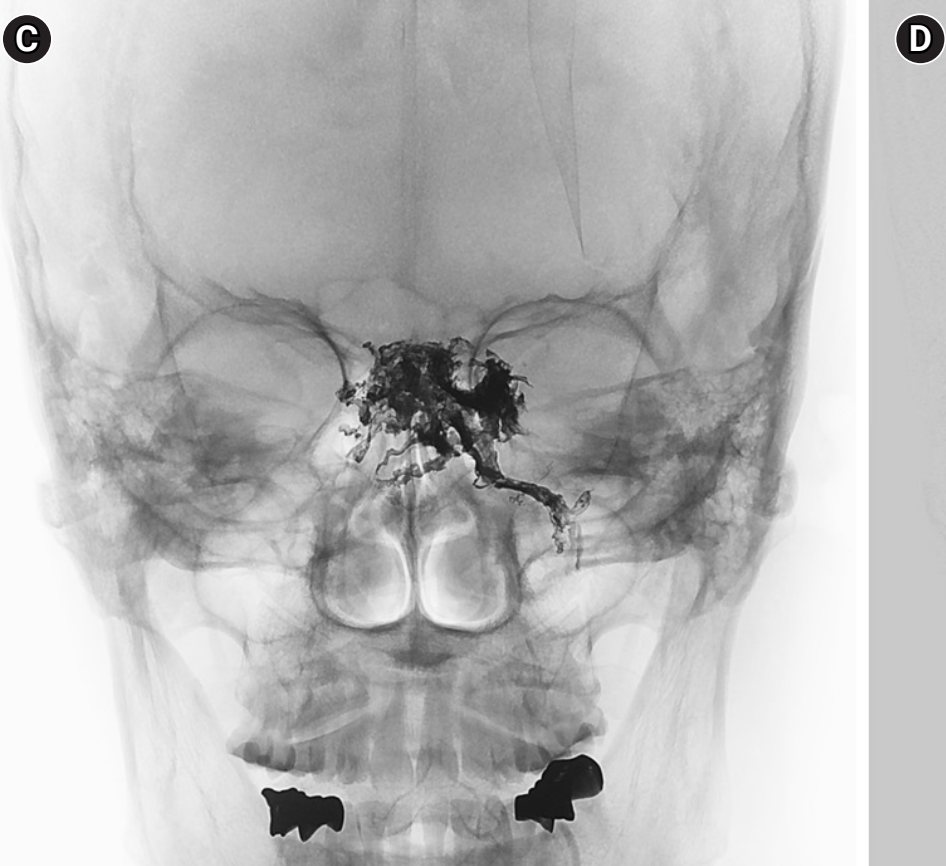

(D)

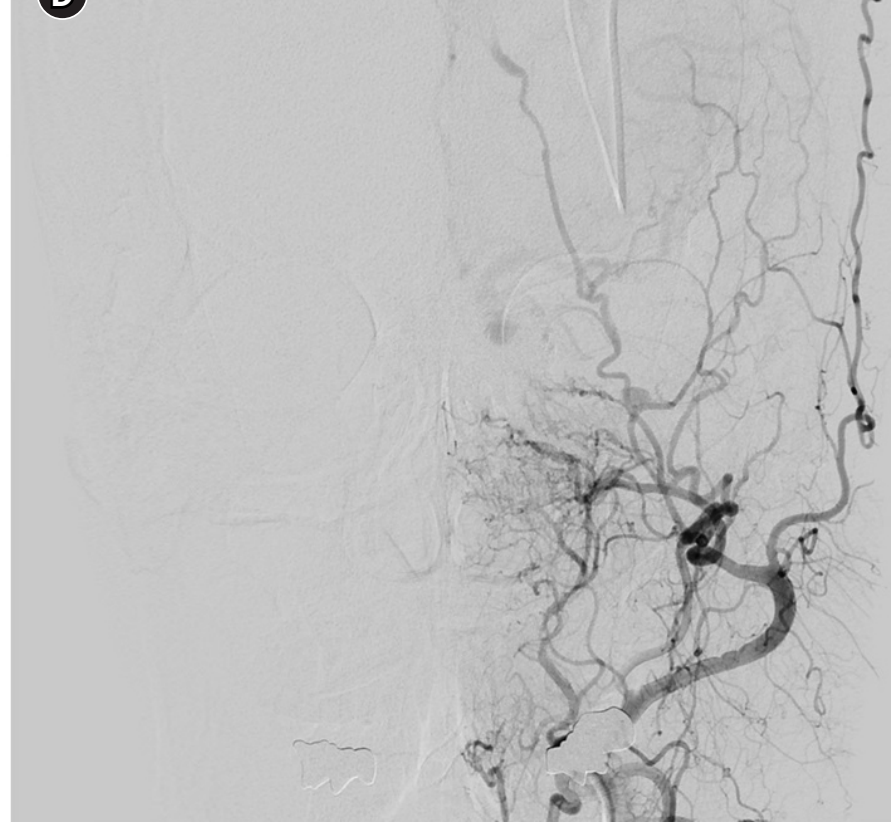

Fig. 2. (A) Native image, lateral projection showing deployed coil at the orifice of superior ophthalmic vein and inflated balloon into the proximal left external carotid artery (ECA). (B) Left ECA angiography during balloon inflation, lateral projection showing diminished blood flow from the left ECA. (C) Final Onyx cast. (D) Final angiography of the left ECA, frontal projection showing complete obliteration of the cavernous sinus dural arteriovenous fistula.

direct injury to the nerve by the coils or the microwire/microcatheter $[1,8]$.

Onyx embolization is less controlled than coil placement, however, this material is associated with a higher rate of complete obliteration [9]. Furthermore, because Onyx is less thrombogen- ic than coils, paradoxical worsening occurs less frequently after Onyx embolization. Nevertheless, paradoxical worsening can occur after Onyx embolization [10], possibly caused by CS thrombosis and swelling, or due to the angiotoxic effect of DMSO [4]. The incidence of Onyx embolization-induced paradoxical wors- 

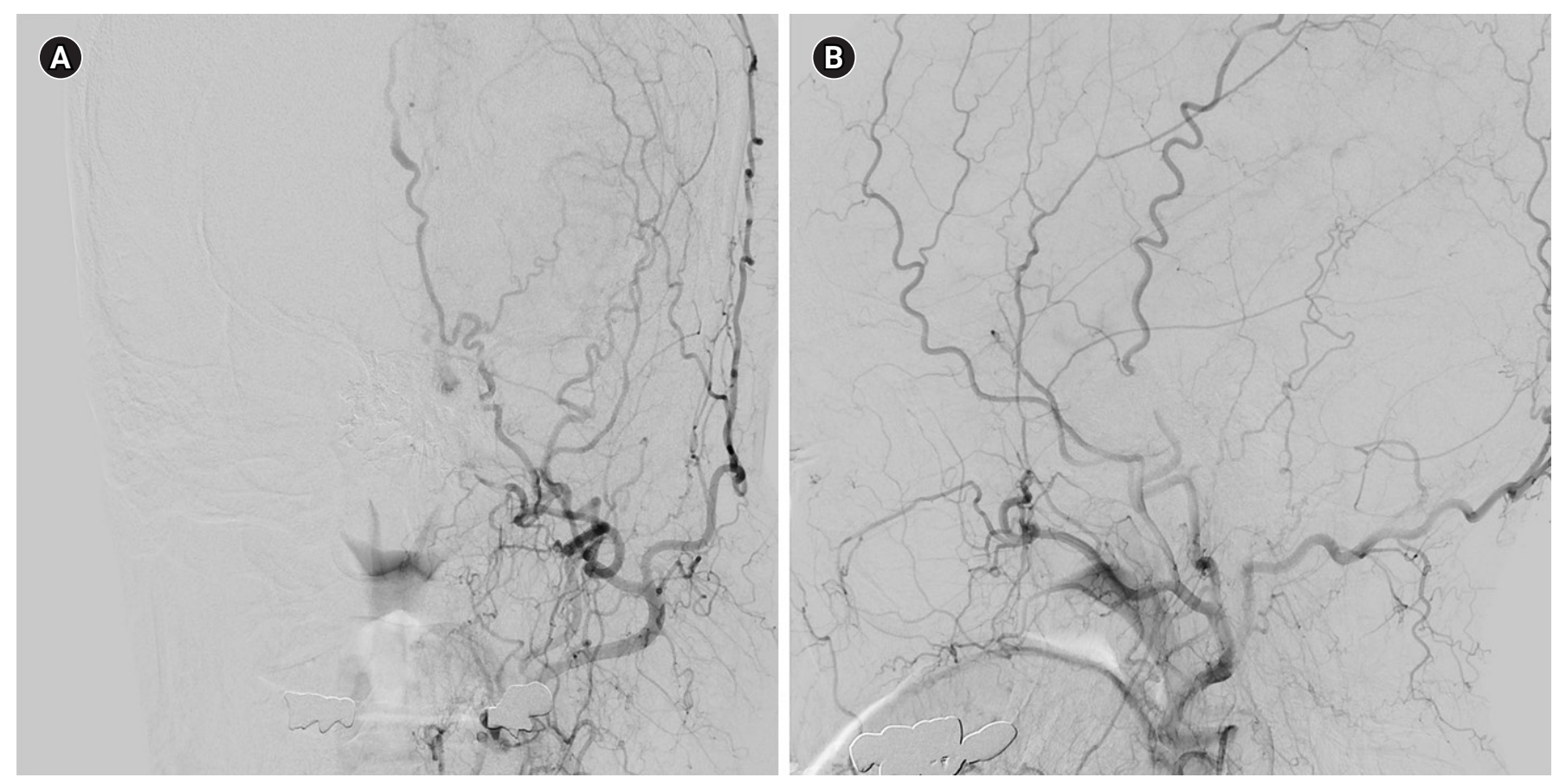

Fig. 3. Left external carotid artery angiography at 6-month post-embolization, (A) frontal projection and (B) lateral projection showing complete obliteration of the cavernous sinus dural arteriovenous fistula.

ening is not known because no large case series or well-controlled studies have addressed the issue. Importantly, most cases of paradoxical worsening after coil embolization or Onyx embolization fully recovered $[10,11]$.

Onyx, which is an ethylene vinyl alcohol copolymer preparation, has several advantages for endovascular treatment. Onyx laminates along the vessel wall and is less adhesive and more cohesive than NBCA. Furthermore, the slower polymerization rate and cohesive nature of Onyx allows it to be injected over a period of several minutes to over an hour, enabling more controlled embolization.

Although several cases of transarterial balloon catheter-assisted Onyx embolization of traumatic carotid cavernous fistulas and of intracranial DAVFs other than CS DAVFs have been reported previously [12-14], ours is the first to describe the transvenous Onyx embolization of a CS DAVF using a balloon catheter on the arterial side to control flow.

When using Onyx, it is essential to allow time for the material to create a plug around the tip of the microcatheter, which enables the forward flow of Onyx. The formation of an Onyx plug in the CS is challenging, given the shunted flow and high pressure. Thus, in previous reports, coils were inserted before injecting Onyx to act as a template for the material $[5,9,15]$.

However, by controlling blood flow, Onyx embolization can be performed without coils. Thus, flow control is an important as- pect of Onyx controllability. Flow can be modulated using selective or nonselective methods. Selective control reduces blood flow from the main feeder of multiple feeding arteries and includes the plug and push, pressure cooker, balloon-assisted embolization, and wedge techniques. Nonselective control reduces the blood flow from multiple feeding arteries by placing a balloon proximal to the common trunk of multiple feeders.

We chose Onyx embolization to treat our patient with CS DAVF because Onyx is less thrombogenic and has a higher rate of complete obliteration. However, the possibility that the shunted flow at the fistula could prevent formation of the Onyx plug or cause the Onyx to migrate to an unintended site necessitated the use of flow control. Selective control was not an option in our case due to the presence of multiple fine feeding arteries. Instead, we used a balloon catheter to control blood flow and injected Onyx into the venous side of the fistula. No unintended Onyx migration occurred, no procedure-related complications, including paradoxical worsening, were observed, and the CS DAVF was completely occluded.

The treatment of DAVFs using transvenous Onyx embolization with arterial flow control has several advantages. Firstly, because Onyx is less thrombogenic than coils, it is associated with a lower rate of paradoxical worsening. Secondly, flow control decreases flow velocity on the venous side of the DAVF, which in turn decreases distal migration of the Onyx. Therefore, the trans- 
venous approach can achieve higher obliteration rates and lower complication rates than coil embolization.

We report the successful endovascular treatment of a CS DAVF. Transvenous Onyx embolization with flow control via temporary balloon occlusion may be a useful technique for the embolization of CS DAVFs with multiple arterial feeders.

\section{ARTICLE INFORMATION}

\section{Conflict of interest}

No potential conflict of interest relevant to this article.

\section{ORCID}

Chul-Hoo Kang, https://orcid.org/0000-0002-4176-0941

Jieun Roh, https://orcid.org/0000-0002-6876-3990

Jeong A Yeom, https://orcid.org/0000-0002-0328-7989

Sang Won Lee, https://orcid.org/0000-0002-3199-7072

Seung Kug Baik, https://orcid.org/0000-0001-5408-747X

\section{Author contributions}

Conceptualization: CHK, SWL and SKB. Data curation \& Formal analysis: CHK and JAY. Visualization \& Writing-original draft: CHK and JR. Writing-review editing: CHK and SKB.

\section{REFERENCES}

1. Kim DJ, Kim DI, Suh SH, Kim J, Lee SK, Kim EY, et al. Results of transvenous embolization of cavernous dural arteriovenous fistula: a single-center experience with emphasis on complications and management. AJNR Am J Neuroradiol 2006; 27:2078-82.

2. Chaloupka JC. Endovascular therapy for dural arteriovenous fistulas. In: Marks MP, Do HM, editors. Endovascular and percutaneous therapy of the brain and spine. Philadelphia: Lippincott Williams \& Wilkins; 2002.p. 217-316.

3. Albuquerque FC, Ducruet AF, Crowley RW, Bristol RE, Ahmed A, McDougall CG. Transvenous to arterial Onyx embolization. J Neurointerv Surg 2014;6:281-5.

4. Elhammady MS, Wolfe SQ, Farhat H, Moftakhar R, Aziz-Sultan MA. Onyx embolization of carotid-cavernous fistulas. J Neurosurg 2010;112:589-94.

5. Kiyosue H, Hori Y, Okahara M, Tanoue S, Sagara Y, Matsumoto $S$, et al. Treatment of intracranial dural arteriovenous fistulas: current strategies based on location and hemodynamics, and alternative techniques of transcatheter embolization. Radiographics 2004;24:1637-53.

6. Roy D, Raymond J. The role of transvenous embolization in the treatment of intracranial dural arteriovenous fistulas. Neurosurgery 1997;40:1133-41.

7. Nishino K, Ito Y, Hasegawa H, Kikuchi B, Shimbo J, Kitazawa K, et al. Cranial nerve palsy following transvenous embolization for a cavernous sinus dural arteriovenous fistula: association with the volume and location of detachable coils. J Neurosurg 2008;109:208-14.

8. Guo H, Yin Q Liu P, Guan N, Huo X, Li Y. Focus on the target: angiographic features of the fistulous point and prognosis of transvenous embolization of cavernous sinus dural arteriovenous fistula. Interv Neuroradiol 2018;24:197-205.

9. de Castro-Afonso LH, Trivelato FP, Rezende MT, Ulhôa AC, Nakiri GS, Monsignore LM, et al. Transvenous embolization of dural carotid cavernous fistulas: the role of liquid embolic agents in association with coils on patient outcomes. J Neurointerv Surg 2018;10:461-2.

10. Lee JM, Whang K, Cho SM, Kim JY, Oh JW, Koo YM, et al. Cranial nerve palsy after onyx embolization as a treatment for cerebral vascular malformation. J Cerebrovasc Endovasc Neurosurg 2017;19:189-95.

11. Jung KH, Kwon BJ, Chu K, Noh Y, Lee ST, Cho YD, et al. Clinical and angiographic factors related to the prognosis of cavernous sinus dural arteriovenous fistula. Neuroradiology 2011; 53:983-92.

12. Kim ST, Jeong HW, Seo J. Onyx embolization of dural arteriovenous fistula, using scepter $\mathrm{C}$ balloon catheter: a case report. Neurointervention 2013;8:110-4.

13. Yu Y, Huang Q, Xu Y, Hong B, Zhao W, Deng B, et al. Use of onyx for transarterial balloon-assisted embolization of traumatic carotid cavernous fistulas: a report of 23 cases. AJNR Am J Neuroradiol 2012;33:1305-9.

14. Shi ZS, Loh Y, Duckwiler GR, Jahan R, Viñuela F. Balloon-assisted transarterial embolization of intracranial dural arteriovenous fistulas. J Neurosurg 2009;110:921-8.

15. He HW, Jiang CH, Wu ZX, Li YX, Lü XL, Wang ZC. Transvenous embolization with a combination of detachable coils and Onyx for a complicated cavernous dural arteriovenous fistula. Chin Med J (Engl) 2008;121:1651-5. 